\title{
Molecular diagnosis of acute and chronic infection of Trypanosoma evansi in experimental male and female mice
}

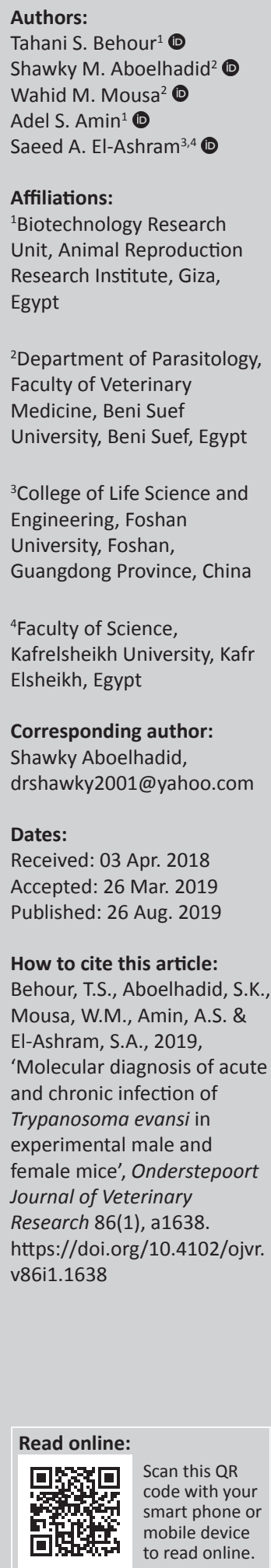

Trypanosoma evansi is enzootic in camels in Egypt, and water buffaloes act as a reservoir for camel infection. Molecular techniques have contributed towards understanding the epidemiology of T. evansi. Trypanosoma evansi was detected in acute and chronic stages of the disease in male and female mice by polymerase chain reaction (PCR) using two primers. Two experiments were conducted. In experiment I, two groups consisting of 26 female and 26 male mice received $10^{4}$ trypanosome by I/P inoculation for each mouse. In experiment II, 42 female and 42 male mice were inoculated I/P with $10^{2}$ trypanosome/mouse. In addition, five mice were kept as uninfected control for each group. Mice were monitored daily for parasitaemia level during the pre-patent period using the micro-haematocrit centrifugation technique (MHCT) and conventional PCR. The primer pairs, (Trypanosoma brucei) TBR1/2 and TeRoTat1.2 (T. evansi Rode Trypanozoon antigen type [RoTat] 1.2), detected the infection after 24 hours earlier than MHCT in both experiments. The course of infection that was detected by MHCT revealed three waves of parasitaemia in female mice and two waves in male mice in the chronic stage of infection. In addition, PCR was able to detect T. evansi in different organs in the chronic stage (i.e. disappearance of parasite from blood). Application of the two primer sets on blood samples from camels showed that all samples were positive by TBR $1 / 2$ primers and only 32 of 44 were positive by TeRoTat1.2 primers. Acutely and chronically Trypanosoma-infected mice were detected by PCR in blood and organs. TBR1/2 primers were more sensitive than TeRoTat1.2 primers in detecting Trypanosoma-infected mice, and more reliable in detecting field-infected camels and excluding carrier animals.

Keywords: Trypanosoma evansi; acute; chronic; mice; PCR; polymerase chain reaction; organs.

\section{Introduction}

Trypanosoma evansi belongs to the genus Trypanosoma and subgenus Trypanozoon, and is the first pathogenic trypanosome to be discovered globally. Trypanosoma evansi was hypothesised to originate from Trypanosoma brucei (TBR), by lacking genes necessary for mitochondrial development with loss of ability to undergo growth and differentiation in the insect vector and adaptation to a non-cyclic mode of transmission for the parasite (Carnes et al. 2015; Luckins 1988). Trypanosoma evansi has been able to spread rapidly by non-specific mechanical vectors, such as tabanids and stomoxes (Herrera et al. 2004; Otto et al. 2010). Trypanosoma evansi is enzootic in camels in Egypt, and water buffaloes act as a reservoir for camel infection (Elhaig, Youssef \& El-Gayar 2013; Hilali et al. 2004). Surra is an insect-borne parasitic disease caused by T. evansi with wide distribution globally. Trypanosoma evansi infects a wide diversity of mammalian hosts, including animals and humans. However, camels, horses and dogs remain the most critical hosts for this parasite, and bovine hosts are very efficient reservoirs (Desquesnes et al. 2013; Fernandez et al. 2009; Rjeibi et al. 2015). The syndromes associated with T. evansi infection are severe and fatal, especially in the late stage of the disease. The disease varies from chronic to lethal acute accompanied with progressive weakness, emaciation, depletion, recurrent fever, enlarged lymph nodes and death (Omer, Mousa \& Al-Wabel 2007; Saleh, Bassam \& Sanousi 2009). The underestimation of the medical and economic impacts of T. evansi has contributed to its ability to spread silently via healthy carriers. Although T. evansi is inapparent in most instances, the parasite affects livestock productivity causing mortality, reduced animal production and reproduction performance, low carcass quality, and decreased animal strength (Desquesnes et al. 2013; Reid 2002). Diagnosis of T. evansi infection relies on the detection of the parasite in the blood or tissue fluids of infected animals. Parasitological techniques cannot

Copyright: @ 2019. The Authors. Licensee: AOSIS. This work is licensed under the Creative Commons Attribution License. 
always detect ongoing infections as the level of parasitaemia is often low and fluctuating, particularly during the chronic stage of the disease, which exhibits very low parasitaemia (Nantulya 1990). Consequently, the sensitivity and specificity of parasitological diagnostic tests are unacceptable in situations where confirmation of presence or absence of T. evansi in livestock is necessary prior to the introduction of new animals or after implementation of control and eradication programmes (Viljoen \& Luckins 2012).

The nucleic acid-based assays are considered to be the most powerful tools for the detection of T. evansi in several animals and vectors (Sukhumsirichart et al. 2000). Molecular techniques enable researchers to identify and characterise the newly introduced T. evansi strains, detect mixed infections, study the disease epidemiology and understand the interaction between vectors and reservoirs (Fernandez et al. 2009). Therefore, the objective of this study was to compare and evaluate the sensitivity and specificity of the two primer sets in the detection of acutely and chronically Trypanosomainfected male and female mice.

\section{Materials and methods}

All procedures for animal infection, euthanasia and sample collections were approved by the Animal Reproduction Research Institute, Agricultural Research Center, Egyptian Committee.

\section{Trypanosoma evansi strain}

Trypanosoma evansi strain (isolated from naturally infected camels) was obtained from the Department of Parasitology, Faculty of Veterinary Medicine, Cairo University. The parasite was propagated in laboratory mice and preserved in liquid nitrogen, according to Shumei et al. (1996), for further processing.

\section{Mice}

Swiss albino mice (73 females and 73 males) weighing $25 \mathrm{~g}-$ $30 \mathrm{~g}$ were purchased from the Laboratory Animal Building, Research Institute of Ophthalmology, Giza. The mice were housed in a pathogen-free environment for 2 weeks prior to the initiation of experiments. The mice were subjected to feed and water ad libitum.

\section{Experiment I}

Two groups of mice, 26 females and 26 males, were kept separately. Twenty-one mice from each group received $10^{4}$ trypanosome/mouse by I/P inoculation (infective dose [ID]), according to Sharma et al. (2012). The other five mice from each group were served as uninfected control groups. Three mice were sacrificed daily from each group after infection. For each mouse, blood samples were collected from a tail vein to detect the pre-patent period and estimate the peak of parasitaemia and molecular assays. In addition, liver, spleen, kidneys, brain and ovaries or testis were collected on 1, 3, 5, and 7 days post-infections (DPI). A section from each organ was preserved at $-20^{\circ} \mathrm{C}$ for molecular examination.

\section{Experiment II}

Two groups of mice, 47 females and 47 males, were kept separately. Forty-two mice from each group were inoculated I/P with $10^{2}$ trypanosome/mouse (ID), according to Sharma et al. (2012). Five mice from each group were served as an uninfected normal control group. Three mice from each group were sacrificed from 1-7 DPI and were examined by micro-haematocrit centrifugation technique (MHCT) to detect the pre-patent period and estimate the peak of parasitaemia. All remaining mice were subsequently followed up biweekly for the assessment of parasitaemic waves during the course of infection by MHCT from peripheral blood. Samples were collected, as mentioned before (see experiment I), from each mouse during parasitaemic and aparasitaemic waves.

\section{Parasitological examination}

All blood samples were collected from caudal vein blood in heparinised tubes and then centrifuged for 5 minutes at 5000 revolutions per minute. The capillary tubes were examined under the microscope $(\times 10)$ for the detection of trypanosomes using MHCT (Woo 1970).

\section{Molecular detection of Trypanosoma evansi in blood and tissue samples of experimentally infected mice in both experiments}

\section{Deoxyribonucleic acid extraction from blood and tissue samples}

DNA was extracted from each blood sample according to the procedure used by Sarataphan et al. (2007). Briefly, $50 \mu \mathrm{L}$ of each blood sample was lysed twice in $500 \mu \mathrm{L}$ of $0.1 \mathrm{M}$ ammonium chloride and then centrifuged. The sediment was re-suspended in $50 \mu \mathrm{L}$ of $0.002 \%$ sodium dodecyle sulphate and $50 \mu \mathrm{L}$ of $5 \%$ Chelex $-100^{\circledR}$ (Sigma) suspension in TE buffer (10 mM Tris-HCl, 0.1 mM EDTA, pH 8.0).

The mixture was heated at $70{ }^{\circ} \mathrm{C}$ for $8 \mathrm{~min}$ followed by heating to $100{ }^{\circ} \mathrm{C}$ for $10 \mathrm{~min}$. Finally, the mixture was centrifuged at $10000 \mathrm{rpm}$ for $5 \mathrm{~min}$ at room temperature, and the supernatant was stored at $-80{ }^{\circ} \mathrm{C}$ for molecular detection of trypanosomes by polymerase chain reaction (PCR). For tissue samples, $0.5 \mathrm{~g}$ of each tissue was washed in $500 \mu \mathrm{L}$ of phosphate-buffered saline and then grinded in liquid nitrogen. The obtained pellet was suspended in $300 \mu \mathrm{L}$ of $10 \%$ Chelex $-100^{\circledR}$ suspension in TE buffer. The tissue samples were subsequently processed as stated above.

\section{Conventional polymerase chain reaction sensitivity for detection of Trypanosoma evansi}

To determine the detection limit of the standard PCR assay and establish a standard dilution for detection, 10-fold serial dilutions of known aliquots of $T$. evansi $\left(1.0 \times 10^{6}\right.$ trypanosomes) were used for seeding the non-infected camel blood. Dilutions were subjected to DNA extraction as 


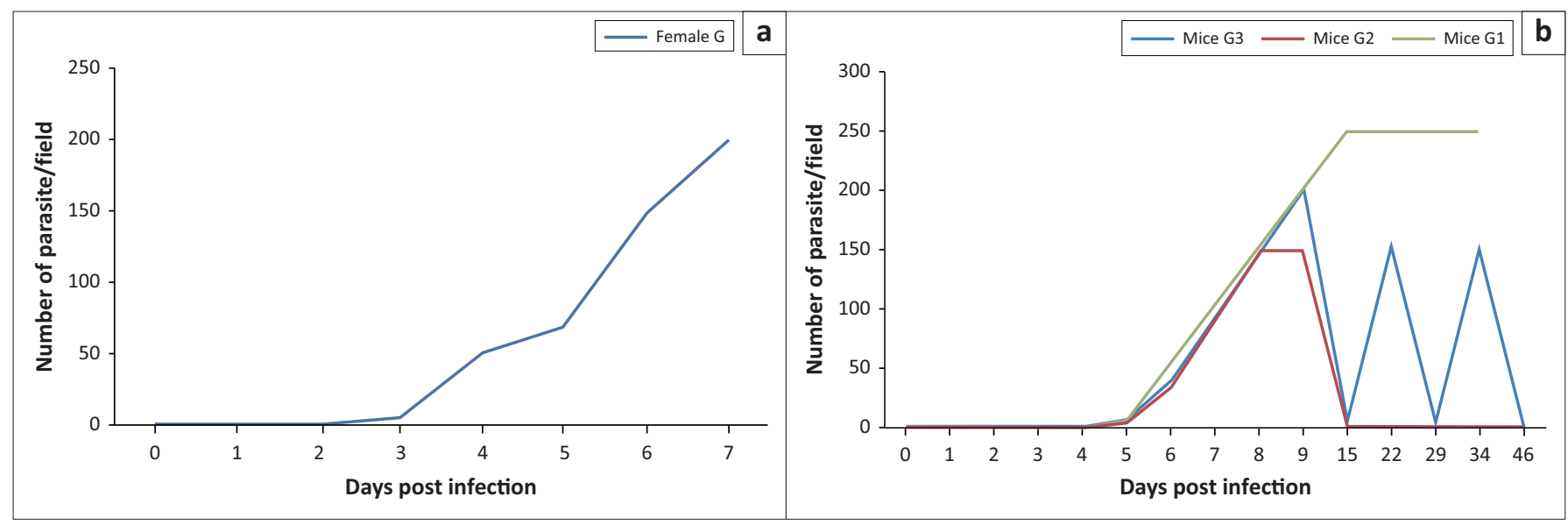

FIGURE 1: Infection in experimentally infected mice. The course of the parasitemia during the period of the experiment I (a) (104 infective dose) and experiment II (b) $\left(10^{2}\right.$ infective dose) by micro-haematocrit centrifugation technique. The days post infection is plotted against the approximate no. of parasite in $50 u$ L blood. The plotted curves represent the different disease patterns obtained in mice during both experiments.

described above and then processed by conventional PCR as described below using TBR F-TBR R (Masiga et al. 1992) and (T. evansi Rode Trypanozoon antigen type) TeRoTat920 F-TeRoTat1070 R (Konnai et al. 2009) primer sets.

\section{Deoxyribonucleic acid amplification by conventional polymerase chain reaction assays on blood and tissue samples from Trypanosoma-infected mice in both experiments}

PCR analysis was done by using primer pairs TBR F-TBR R (Masiga et al. 1992) and TeRoTat920 F-TeRoTat1070 R (Konnai et al. 2009) in standard PCR procedures. Briefly, the PCR mixture of $25 \mu \mathrm{L}$ contained 2X Taq Master Mix, 25 pmol of each primer, $2 \mu \mathrm{L}$ of Deoxyribonucleic acid (DNA) template and up to $25 \mu \mathrm{L}$ nuclease-free water were added. PCR using TBR F (5'-GAA TAT TAA ACA ATG CGC AG-3') and TBR R (5'-CCA TTT ATT AGC TTT GTT GC-3') was performed in a thermocycler (Nexus Gradient Eppendorf, Germany) as follows: an initial denaturation step at $95{ }^{\circ} \mathrm{C}$ for $4 \mathrm{~min}$, 30 cycles of denaturation at $95^{\circ} \mathrm{C}$ for 45 seconds, annealing at $52{ }^{\circ} \mathrm{C}$ for $45 \mathrm{~s}$, and extension at $72{ }^{\circ} \mathrm{C}$ for $60 \mathrm{~s}$ and final extension at $72{ }^{\circ} \mathrm{C}$ for $10 \mathrm{~min}$. PCR using TeRoTat920 $\mathrm{F}$ (5'-CTG AAG AGG TTG GAA ATG GAG AAG-3') and TeRoTat1070 R (5'-GTT TCG GTG GTT CTG TTG TTG TTA-3') was carried out in a thermocycler (Eppendorf Thermal Cycler, Germany) as follows: an initial denaturation step at $95{ }^{\circ} \mathrm{C}$ for $4 \mathrm{~min}, 35$ cycles of denaturation at $95^{\circ} \mathrm{C}$ for $60 \mathrm{~s}$, annealing at $52^{\circ} \mathrm{C}$ for $60 \mathrm{~s}$, and extension at $72{ }^{\circ} \mathrm{C}$ for $60 \mathrm{~s}$ and final extension at $72{ }^{\circ} \mathrm{C}$ for $10 \mathrm{~min}$. Amplicons were resolved on a $1.5 \%$ agarose gel stained with ethidium bromide (Sigma) and photographed under ultra violet (UV) light (Sambrook and Russell 2001). Positive control (T. evansi DNA) and negative control (reaction mixtures without DNA) were included in each PCR run.

\section{Application of polymerase chain reaction assay on field blood samples from camels}

Forty-four camels' blood samples were collected in sterile heparinised tubes from different locations in Giza and Nobariya provinces for detection and isolation of T. evansi. Each sample was tested by MHCT, and $0.5 \mathrm{~mL}$ of blood was

\begin{tabular}{|c|c|c|}
\hline Item & Experiment I & Experiment II \\
\hline Infective dose & $10^{4}$ Parasite/mouse & $10^{2}$ Parasite/mouse \\
\hline \multirow{2}{*}{$\begin{array}{l}\text { Survival duration of } \\
\text { infected mice }\end{array}$} & \multirow[t]{2}{*}{ 7-9 days } & 12-22 days for male mice \\
\hline & & $12-46$ days for female mice \\
\hline Parasitaemic waves & 1 & 3 \\
\hline Chronic waves & None & 3 \\
\hline \multicolumn{3}{|l|}{ Pre-patent period } \\
\hline MHCT & 3 days & 5 days \\
\hline PCR & $24 \mathrm{~h}$ & $24 \mathrm{~h}$ \\
\hline
\end{tabular}

MHCT, micro-haematocrit centrifugation technique; PCR, polymerase chain reaction.

inoculated I/P into a laboratory mouse to investigate parasitic infection. DNA was extracted, and the PCR assay was conducted as mentioned before.

\section{Ethical considerations}

Ethical approval was provided by the Committee at the Animal Reproduction Research Institute Agricultural Research Center, Egypt (23-2016).

\section{Results}

\section{Following-up the course of infection in experimentally infected mice}

Different parasitaemic patterns were appeared in the infected groups according to the ID in mice. In experiment I, the pre-patent period (appearance of parasite in blood) was detected at 3 DPI and reached the peak of parasitaemia at 7 DPI (Figure 1, experiment I). In experiment II (Figure 1, experiment II), the pre-patent period was determined at 5 DPI and parasitaemia peaked at 9 DPI, and three infection patterns were observed as follows: six mice showed persistent parasitaemia and died within 12-34 DPI (G1). In contrast, other six mice showed the disappearance of parasitaemia at 15 DPI and remained stable at this level until the end of the experiment (G2). Twelve mice of the group (G3) displayed three waves of parasitaemia at 9, 22 and 34 DPI, with the disappearance of parasitaemia at 15, 29 and 46 DPI (Table 1). 


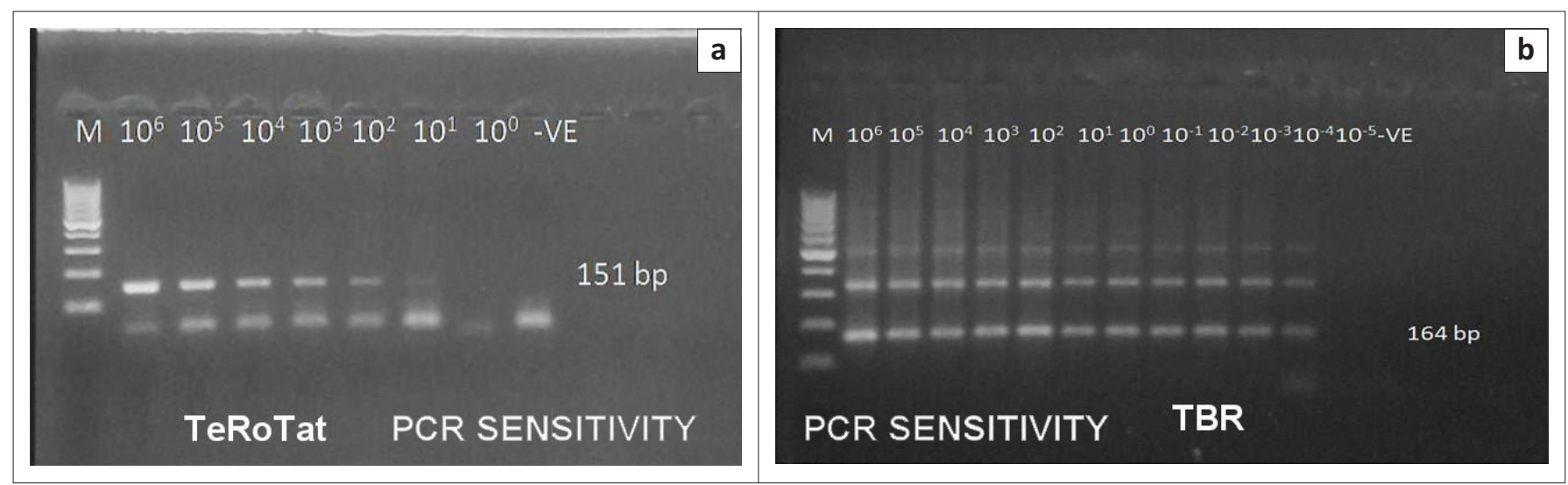

bp, base pairs; TBR, Trypanosoma brecei; TeRoTat, T. evansi Rode Trypanozoon antigen type (RoTat) 1.2 Variable Surface Glycoprotein (VSG) gene; PCR, polymerase chain reaction.

FIGURE 2: Polymerase chain reaction detection limit by conventional polymerase chain reaction. Lane M: 100 base pairs molecular weight Deoxyribonucleic acid marker. Lanes 1-12: different dilutions and -ve: negative control. Trypanosoma brucei $1 / 2$ detects Trypanosoma evansi at lower dilutions (10-4 parasite/mL) than T. evansi Rode Trypanozoon antigen type $1 / 2$ (10 parasite/mL of blood). (a) TeRoTat; (b) TBR.

\section{Detection limit of Trypanosoma evansi using conventional polymerase chain reaction}

PCR sensitivity was estimated using two primer sets TeRoTat1.2 and TBR1/2 with 10-fold serial dilution of $10^{6}$ parasites/mL. Using TeRoTat1.2 primer set, the minimal detection limit was 10 parasites/mL blood. No extra bands were amplified except the $151 \mathrm{bp}$ (base pairs) target DNA band (Figure 2a). Employing TBR1/2 primer set, the lowest detection limit was 0.0001 parasites $/ \mathrm{mL}$ blood despite the appearance of two extra non-specific bands in addition to the $164 \mathrm{bp}$, specifically amplified band (Figure 2b).

\section{Conventional polymerase chain reaction detection of Trypanosoma evansi in blood in both experiments}

It was found that the assay was able to detect T. evansi DNA at 1 DPI in both experiments. High detection sensitivity was obtained by using TBB1/2 primer sets (Figures 3a and 4a) with convenient band intensity on the agarose gel throughout the course of infection. However, by using RoTat1.2 primer sets, the intensity of the amplified bands was clearly observed and increased gradually from the first DPI until the peak of parasitaemia in both experiments (Figures $3 \mathrm{~b}$ and $4 \mathrm{~b}$ ). It was observed that there was no variation in the results between female and male mice.

\section{Detection of Trypanosoma evansi in different female and male organs in both experiments}

The PCR technique could detect the infection at 24 hours post infection (PI) in both experiments in different examined organs, such as liver, spleen, kidney, testis and brain. The specific bands of the used primers appeared at $164 \mathrm{bp}$ and $151 \mathrm{bp}$ DNA fragments for TBR and TeRoTat primers, respectively. Furthermore, TBR $1 / 2$ primers displayed clear bands at 1 DPI, and TeRoTat1.2 primers showed a faint band at 1 DPI, with an increased band intensity as the infection progressed towards the parasitaemic stage (Figures 5 and 6). In addition, in the chronic stage, no variation was detected between the used primers (Figure 7).

\section{Detection and isolation of Trypanosoma evansi from clinical samples of camels}

All blood samples of camels were negative for T. evansi by MHCT or mouse inoculation. Meanwhile, PCR showed that all the tested samples were positive for the presence of the parasite using TBR1/2 primer sets. However, by using TeRoTat1.2 primer, only 32 out of 44 animals were positive for T. evansi infection (Figure 8).

\section{Discussion}

Molecular diagnostic techniques represent essential tools for the detection of T. evansi infection and are widely spread in the detection of Surra globally because they are rapid, accurate and reliable (Desquesnes \& Davila 2002; Sengupta et al. 2010). Monitoring parasitiaemic level in T. evansi is important for evaluating the health status of the host, determination of disease stage and risk of transmission of disease between animals in the field. Experimental infection of T. evansi was done in mice with two different inoculation doses to follow up the disease and determine which technique is more suitable technique for the early detection of T. evansi. Infection of mice with $10^{4}$ and $10^{2}$ trypanosomes in experiment I and experiment II, respectively, showed variable disease patterns, which could be ascribed to the inoculum dose and sex of mice. Microscopic examination by MHCT showed no difference in parasitaemia in the prepatent periods between male and female mouse groups in experiment I 3 DPI. However, the progress of infection was delayed in male mice compared to female mice as the peaks of parasitaemia were achieved earlier in female than male mice. Differences in infection progress and parasitaemic peaks in T. evansi infection are sex dependant, and may be influenced by a stronger immune response against $T$. brucei in male mice compared to female ones Carvalho et al. (2018).

All remaining Trypanosoma-infected mice were died by the 9 DPI because of acute parasitaemia. In experiment II (10² ID), the pre-patent period was delayed 2 days before compared 

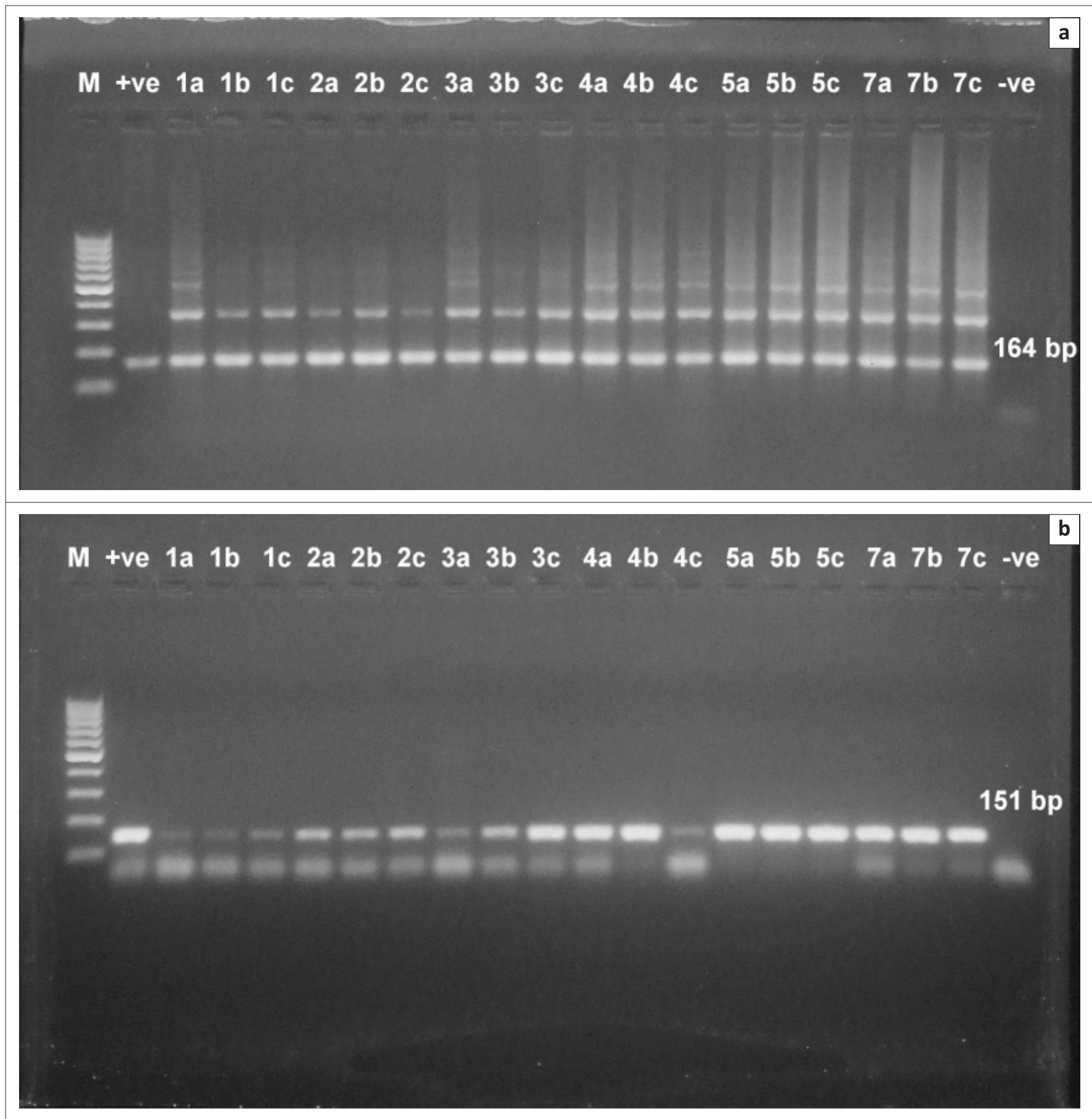

bp, base pairs

FIGURE 3: Direct polymerase chain reaction from mouse blood injected by $10^{4}$ trypanosome. (a) Polymerase chain reaction amplification using Trypanosoma brucei $1 / 2$ primer sets. The band 164 base pairs was high intensity and consistently visible throughout the course of infection. (b) Polymerase chain reaction amplification using T. evansi Rode Trypanozoon antigen type 1.2 primer sets. The bands intensity was clearly observed and increased gradually from the first day post infection until the peak of parasitemia. M: 100 base pair molecular weight Deoxyribonucleic acid marker, +ve: positive control, -ve: negative control, Numbers: days post infection. Letters: mice were sacrificed at day $1,3,5$ and 7 post infection.

to experiment I as a result of decreased inoculum dose. Similar results were observed by Sharma et al. (2012) after T. evansi experimental infection in mice, and the parasite was detected at 3 days and 4.5 days post-inoculation of $10^{4}$ and $10^{2}$ parasites, respectively.

The different patterns of infection observed after inoculation of $10^{2}$ parasites are a reflection of levels of immune response elicited among animals. Female mice showed consistent parasitaemia until death (G1), which can be ascribed to a depressed immune status usually observed in the acute form of the disease.

A persistent chronic undetectable infection in G2 is a reflection of adaptive immune resistance against infection, which represents a carrier state. Fluctuating parasitaemia throughout the course of infection in G3 mirrored antigenic variation among the strains of $T$. evansi and evasion of 

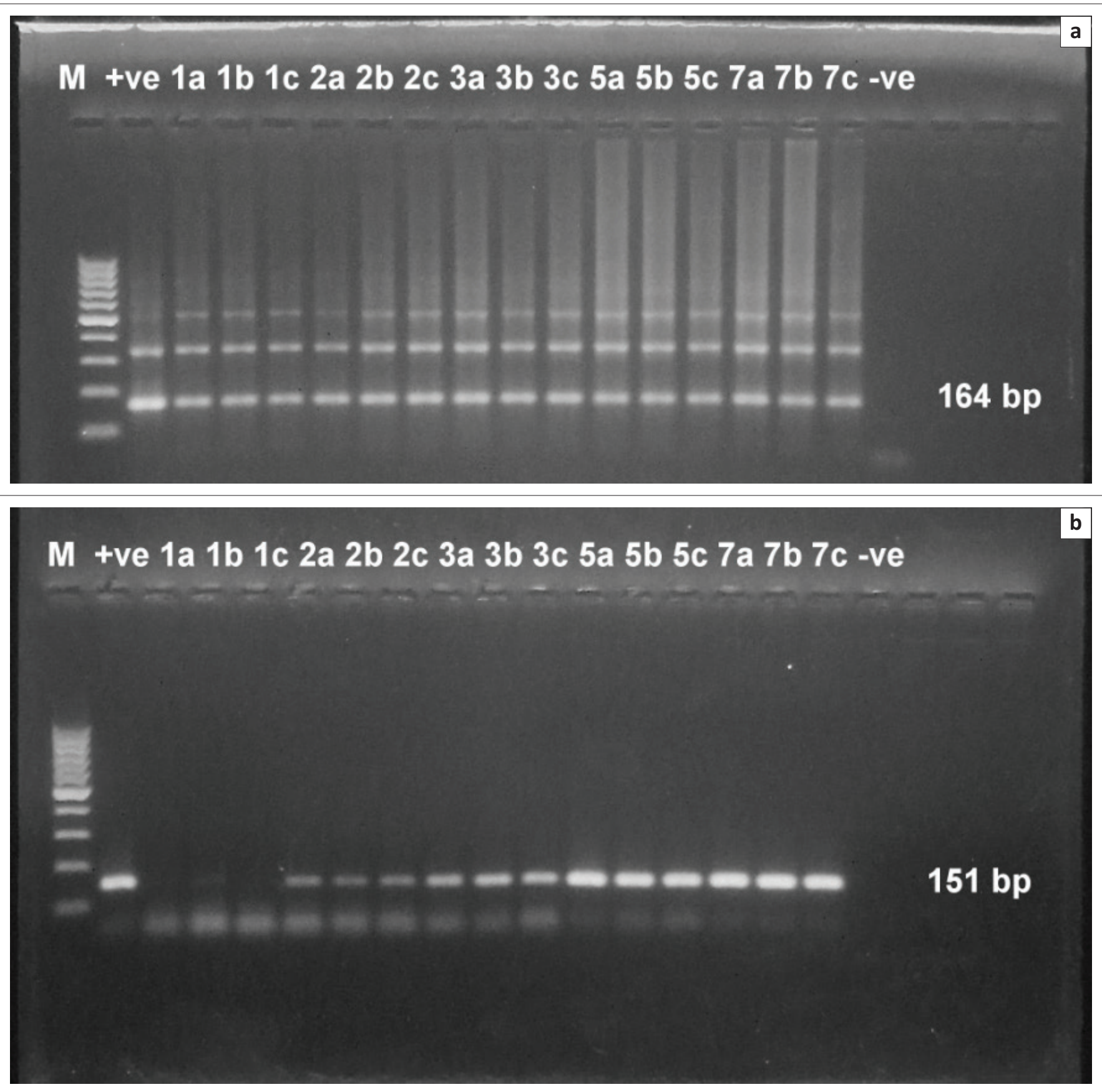

bp, base pairs.

FIGURE 4: Direct polymerase chain reaction from mouse injected with $10^{2}$ trypanosome. (a) Polymerase chain reaction amplification using Trypanosoma brucei $1 / 2$ primer sets. (b) Polymerase chain reaction amplification using T. evansi Rode Trypanozoon antigen type 1.2 primer sets. M: 100 base pair molecular weight Deoxyribonucleic acid marker, +ve: positive control, -ve: negative control, Numbers: days post infection. Letters: mice were sacrificed at day 1, 3, 5 and 7 post infection.

host immune response (Maudlin, Holmes \& Miles 2004). The mechanism is a result of the parasite's ability to periodically switch its major variant surface glycoprotein yielding a parasitaemic relapse (Herrera et al. 2004).

Two parasitaemic waves were observed in male mice. Most of males died from acute parasitaemia where only three mice showed one wave of parasitaemic disappearance and were dead by the second wave of parasitaemia. When the results of MHCT (parasitological test) and PCR (molecular technique) were compared, conventional PCR with TBR1/2 and TeRoTat1.2 primer sets was able to detect the parasite as early as 1 DPI in mice. However, MHCT detected parasite at 3 DPI in experiment I and at 5 DPI in experiment II. All tests were able to detect a peaking parasitaemia.

These results are in line with those of previous studies (Ashour et al. 2013; Sengupta et al. 2010). However, Fernandez et al. (2009) determined the pre-patency 12 hours post infection in mice by TBR1/2 and 1 DPI by ITS1 primers sets. Striking differences in the intensity of the bands amplified by TeRoTat1.2 primer sets from day 1 until the appearance of a 


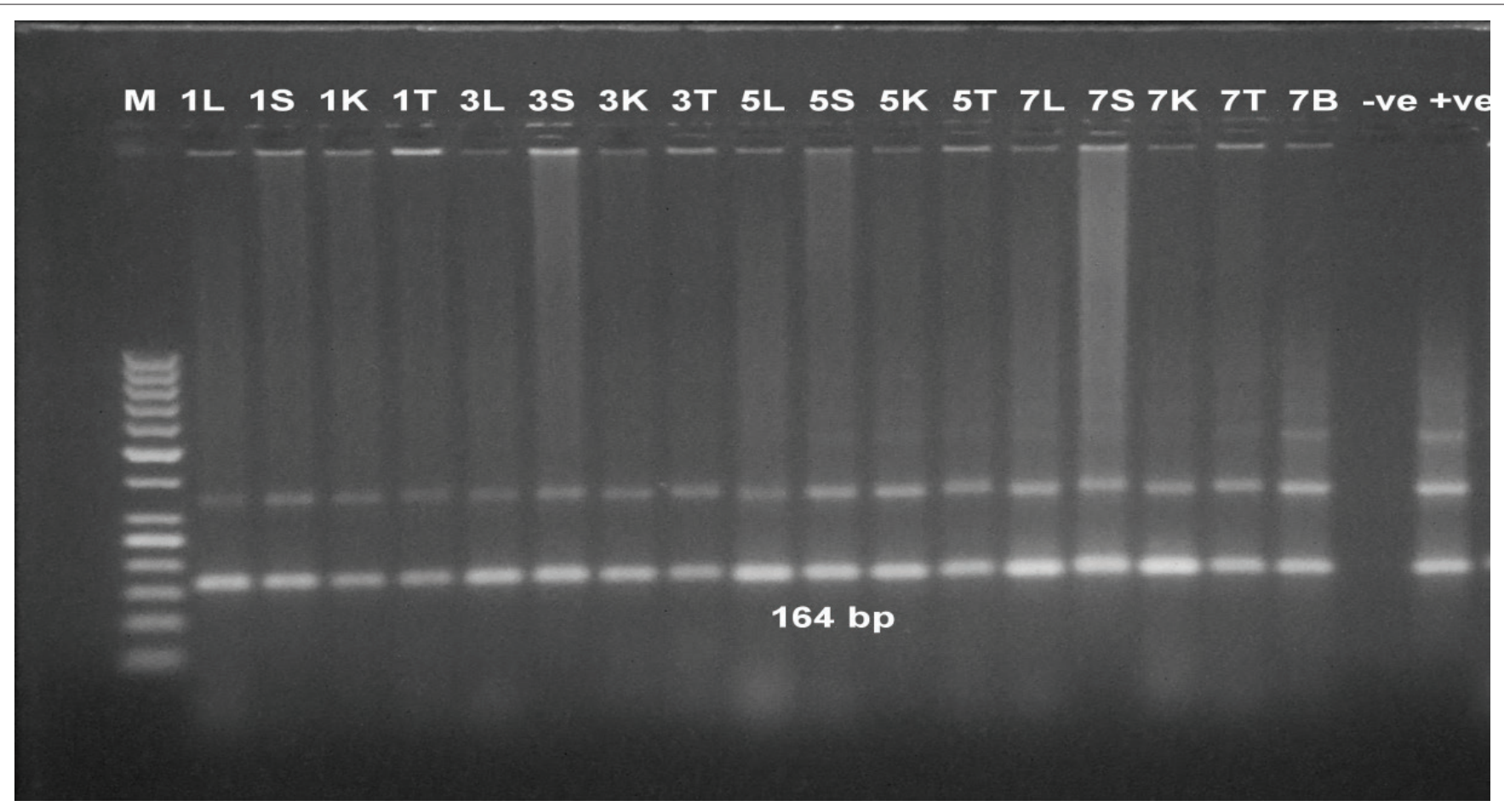

bp, base pairs.

FIGURE 5: Polymerase chain reaction R amplification of Deoxyribonucleic acid extracted from tissues of infected male mice (parasitaemic stage) using Trypanosoma brucei primer set. M: 50 base pairs molecular weight Deoxyribonucleic acid marker, +ve: positive control, -ve: negative control, 1, 3, 5, 7: days post infection and L (liver, ) $\mathrm{S}$ (spleen), $\mathrm{K}$ (kidneys), T (testes) and B (brain).

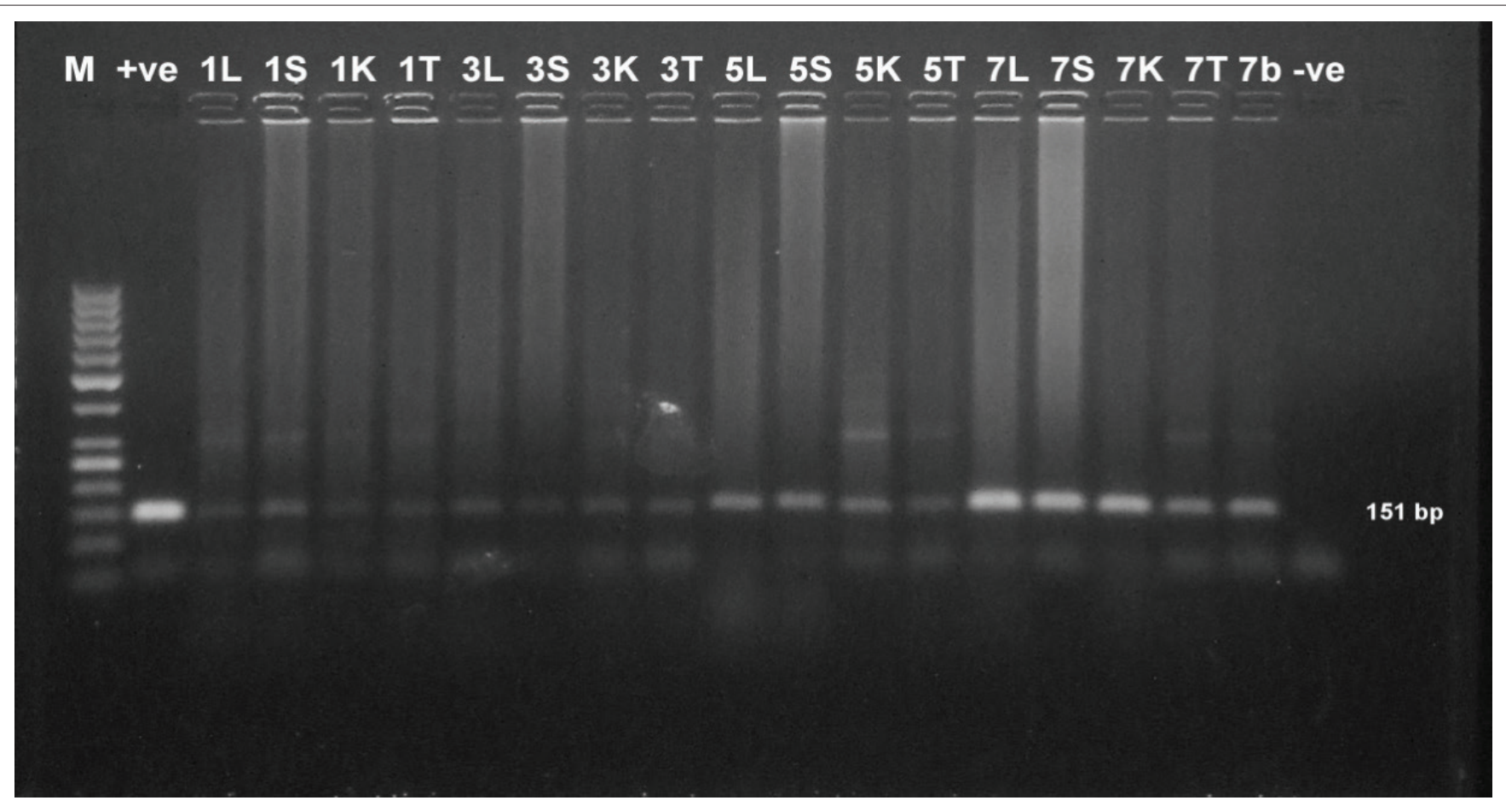

bp, base pairs

FIGURE 6: Polymerase chain reaction amplification of Deoxyribonucleic acid extracted from tissues of infected male mice (parasitaemic stage) using T. evansi Rode Trypanozoon antigen type primer set. M: 50 base pairs molecular weight Deoxyribonucleic acid marker, +ve: positive control, -ve: negative control, 1, 3, 5, 7: days post infection and L (liver), S (spleen), K (kidneys), T (testes) and B (brain).

consistent parasitaemia were ascribed to differences in the parasite count in the blood samples. González et al. (2006) and Fernandez et al. (2009) confirmed that the proportion of DNA is usually a reflection of the number of the parasite in a blood sample. Therefore, they recommended the use of at least $100 \mathrm{ng}$ DNA in the sample when parasitaemia is lower than $10^{3}$ parasites $/ \mathrm{mL}$ to ensure the detection of the parasite by PCR assay. 

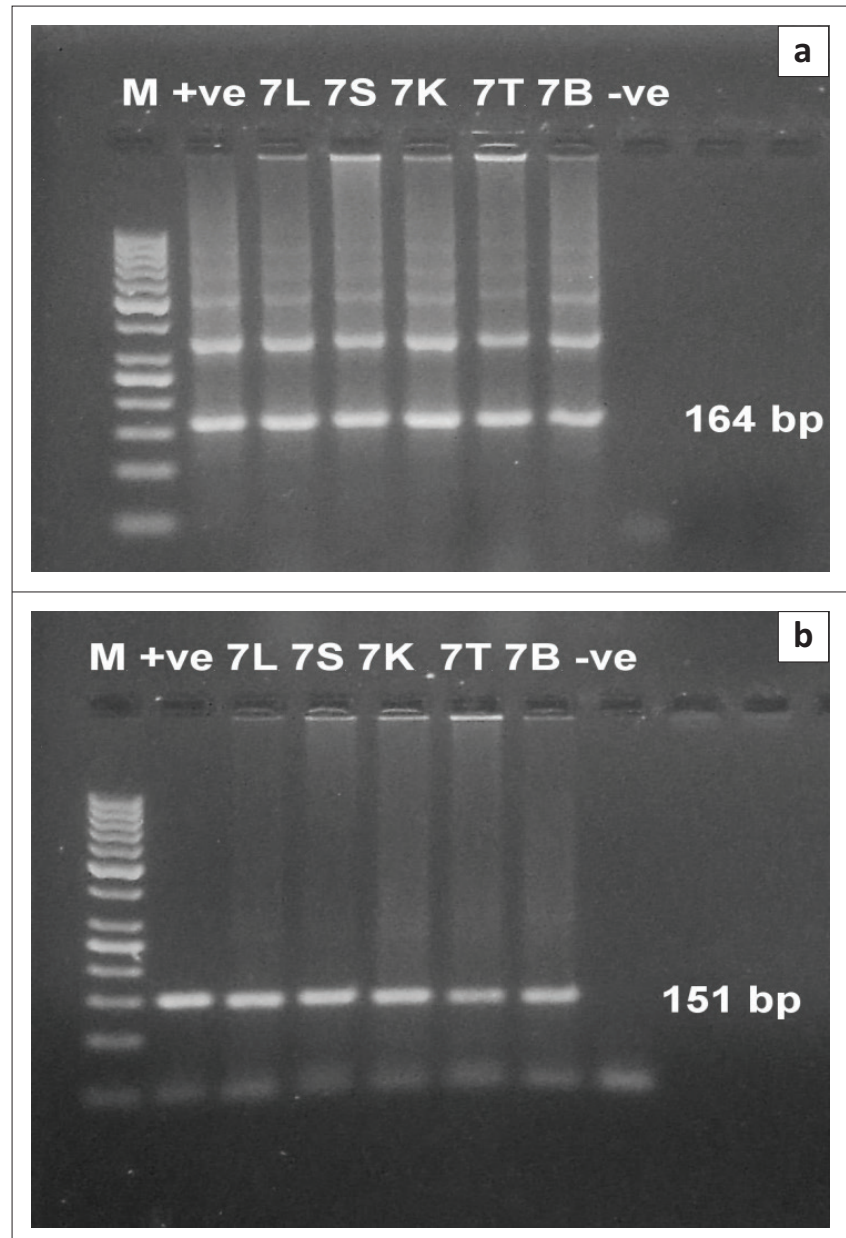

bp, base pairs

FIGURE 7: Polymerase chain reaction amplification of Deoxyribonucleic acid extracted from tissues of infected male mice (chronic) using (a) Trypanosoma brucei primer set and (b) T. evansi Rode Trypanozoon antigen type primer set. M: 50 base pairs molecular weight Deoxyribonucleic acid marker, +ve: positive control, -ve: negative control, 7: days post infection and L (liver), S (spleen), K (kidneys), T (testes) and B (brain).
In TBR1/2 PCR, the intensity of the amplified bands showed little or no difference through the course of infection. This corresponded to the high number of repeat copies of the target sequence, which overcomes low parasitic DNA concentration in the sample.

In the current study, SYBR Green real-time PCR assay was carried out using TeRoTat1.2 primer sets, as described by Konnai et al. (2009). Conventional PCR results were able to detect the pre-patent periods (i.e. appearance of parasite in blood) at 1 DPI in both experiments I and II in mice. These results were further confirmed by melting curve analysis, which was rapid and avoided the downstream procedure of the conventional PCR. Taylor, Boyle and Bingham (2008) detected the parasite 6 DPI in rats injected with $10^{4}$ trypanosomes using ITS-1 TaqMan real-time PCR; however, Sharma et al. (2010) detected the parasite 1.5 DPI in mice infected with $10^{4}$ parasites and 3 DPI with $10^{2}$ parasites by the same assay. Discrepancies between our results and those obtained in previous studies may be because of variations in real-time conditions and different target sequences used in the techniques. Animals infected with T. evansi are characterised by fluctuating parasitaemia as a result of interactions between the host immune response and the ability of the parasite to evade immunity by antigenic variation. Parasitaemia is usually accompanied by the rise and fall of body temperature of the host (Dargantes et al. 2009). During these periods, the demonstration of T. evansi in the blood of animals is obvious; however, low-level parasitaemia results in the difficulty of parasite detection.

The polymerase chain reaction was able to detect T. evansi during the chronic phase of the disease in mice, while MHCT could not. The limited sensitivity and false-negative results of MHCT may be attributed to the fluctuation of parasitaemia

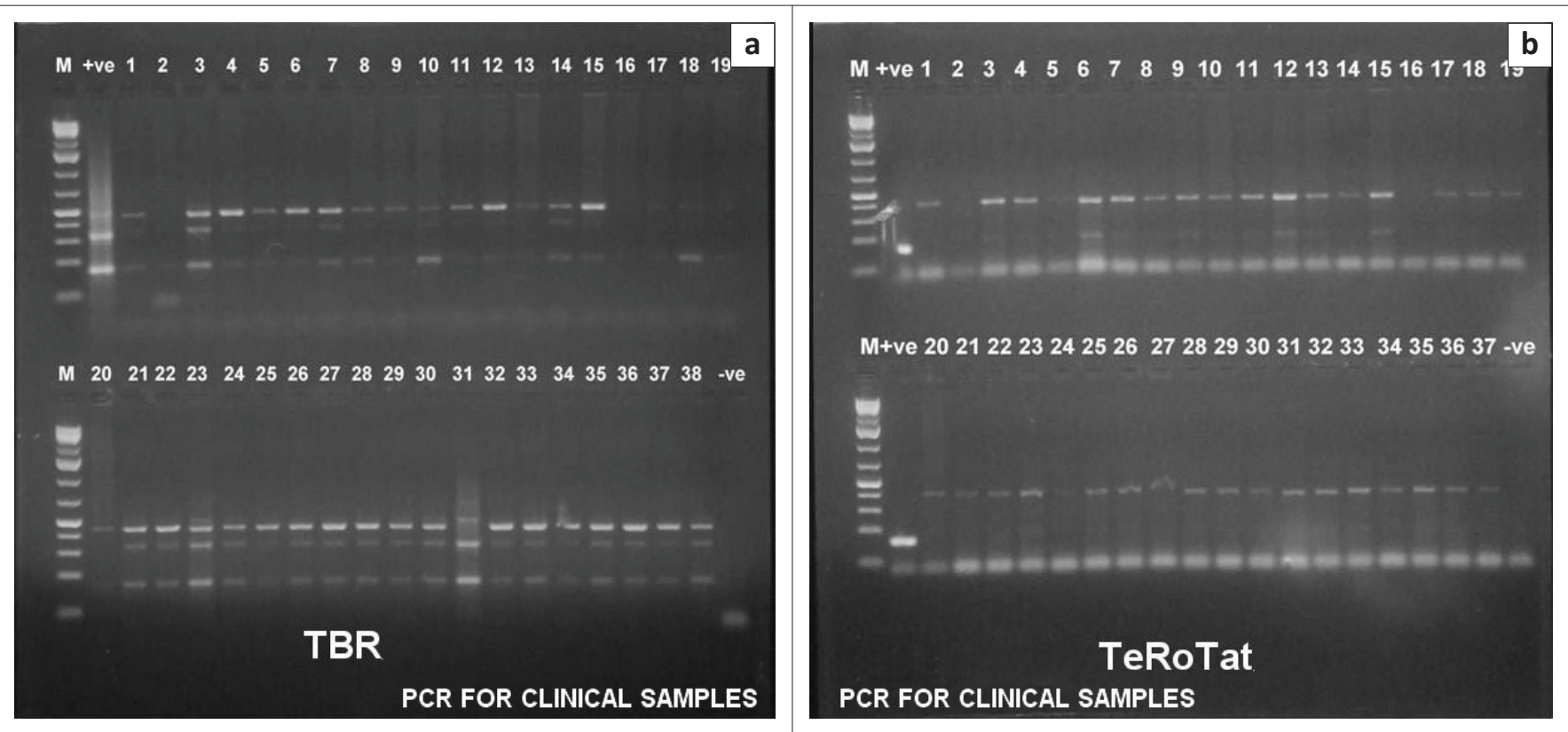

PCR, polymerase chain reaction; TBR, Trypanosoma brucei; TeRoTat, T. evansi Rode Trypanozoon antigen type (RoTat) 1.2 Variable Surface Glycoprotein (VSG).

FIGURE 8: Polymerase chain reaction results of field blood samples with Trypanosoma brucei 1/2 (164 base pairs) and T. evansi Rode Trypanozoon antigen type (RoTat) 1.2. (151 base pairs) primers sets: M: 100 base pairs molecular weight Deoxyribonucleic acid marker, +ve: positive control Trypanosoma evansi Deoxyribonucleic acid and -ve: negative control. (a) TBR and (b) TeRoTat 
and the presence of parasite with low number (Nantulya 1990). Our results are in agreement with those obtained by Ashour et al. (2013) and Ramírez-lglesias et al. (2011) in mice and rabbits, respectively.

Differences between our results and those obtained in previous studies may also be because of diversity of trypanosome strains, different PCR conditions, different primer sets and DNA extraction methods, as mentioned by Fernandez et al. (2009). In this work, Chelex resin was used for DNA extraction from blood samples. The method provided high DNA yield with convenient purity, and was less laborious and overcame the toxic effect and risk of using organic extraction methods (Herrera et al. 2005).

Application of PCR for T. evansi field diagnosis in camels showed variable results among the primers sets. The MHCT and mouse inoculation were not able to detect the parasite in the field samples. This might have been influenced by preservation methods and the duration transportation of samples before laboratory examination. In the same vein, Holland et al. (2001) reported that trypanosomes in samples from animals with high ( $>10^{4}$ trypanosomes $/ \mathrm{mL}$ of blood) and low parasitaemia (250 trypanosomes $/ \mathrm{mL}$ of blood) could not be detected beyond 8 and $3 \mathrm{~h}$ after storage at $4{ }^{\circ} \mathrm{C}$ and $27{ }^{\circ} \mathrm{C}$, respectively. However, positive results were recorded for all samples using conventional PCR and TBR1/2 primer sets, where TeRoTat1.2 PCR was able to detect 32 out of 44 samples.

The low sensitivity of the RoTat1.2 PCR compared with that obtained by TBR1/2 was attributed to several factors such as number of copies of the target DNA sequence on the genome, parasitaemic level, parasitic DNA concentration and nonRoTat1.2 (Variable Surface Glycoprotein) VSG T. evansi variant existence that was previously reported in Kenya (Sengupta et al. 2010). Similar results were obtained by Elhaig et al. (2013), who reported that TBR primers showed higher sensitivity and specificity than five other primer sets for the detection of T. evansi and were able to detect parasitaemia below one parasite per millilitre of blood.

In conclusion, this study demonstrated that PCR was accurate, sensitive and reliable in the detection of the early T. evansi-infected mice, and also able to discriminate chronically infected carrier animals. In addition, PCR with TBR1/2 was more sensitive than TeRoTat1.2. However, TBR1/2 could detect field infection even when samples were negative by conventional methods. Therefore, this study will contribute towards understanding the course of the disease and finding suitable diagnostic tools for T. evansi. Furthermore, the use of molecular PCR for screening of newly introduced animals will help in excluding the carrier animals and detecting the early infected animals for saving free herds.

\section{Acknowledgements}

The authors would like to thank the faculty and staff members of the Department of Parasitology, Faculty of
Veterinary Medicine, Cairo University, for providing them with Tyrpanosoma evansi.

\section{Competing interests}

The authors declare that they have no financial or personal relationships that may have inappropriately influenced them in writing this article.

\section{Authors' contributions}

All authors contributed equally to this work.

\section{Funding information}

This research received no specific grant from any funding agency in the public, commercial or not-for-profit sectors.

\section{Data availability statement}

Data sharing is not applicable to this article as no new data were created or analysed in this study.

\section{Disclaimer}

The views and opinions expressed in this article are those of the authors and do not necessarily reflect the official policy or position of any affiliated agency of the authors.

\section{References}

Ashour, A., Abou El-Naga, T., Barghash, S. \& Salama, M., 2013, 'Trypanosoma evansi: Detection of Trypanosoma evansi DNA in naturally and experimentally infected animals using TBR1 and TBR2 primers', Experimental Parasitology 134(2013) 109-114. https://doi.org/10.1016/j.exppara.2013.02.003

Carnes, J., Anupama, A., Balmer, O., Jackson, A., Lewis, M., Brown, R. et al., 2015, 'Genome and phylogenetic analyses of Trypanosoma evansi reveal extensive similarity to $T$. brucei and multiple independent origins for Dyskinetoplasty', PLoS Neglected Tropical Diseases 9(1), e3404. https://doi.org/10.1371/journal. pntd.0003404

Carvalho, T., Trindade, S., Pimenta, S., Santos, A.B., Rijo-Ferreira, F. \& Figueiredo, L.M., 2018, 'Trypanosoma brucei triggers a marked immune response in male reproductive organs', PLoS Neglected Tropical Diseases 12(8), e0006690. https:// doi.org/10.1371/journal.pntd.0006690

Dargantes, A.P., Mercado, R.T., Dobson, R.J. \& Reid S.A., 2009, 'Estimating the impact of Trypanosoma evansi infection (surra) on buffalo population dynamics in southern Philippines using data from cross-sectional surveys', International Journal of Parasitology 39(10), 1109-1114. https://doi.org/10.1016/j.ijpara.2009.02.012

Desquesnes, M. \& Davila, A.M.R., 2002, 'Applications of PCR-based tools for detection and identification of animal trypanosomes: A review and perspectives', Veterinary Parasitology 109(3-4), 213-231. https://doi.org/10.1016/S03044017(02)00270-4

Desquesnes, M., Holzmuller, P., Lai, D., Dargantes, A., Lun, Z. \& Jittaplapong, S., 2013 'Trypanosoma evansi and Surra: A review and perspectives on origin, history, distribution, taxonomy, morphology, hosts, and pathogenic effects', BioMed Research International 2013, 194176, 1-22.

Elhaig, M., Youssef, A. \& El-Gayar, A., 2013, 'Molecular and parasitological detection of Trypanosoma evansi in Camels in Ismailia, Egypt', Veterinary Parasitology 198(12), 214-218. https://doi.org/10.1016/j.vetpar.2013.08.003

Fernandez, D., Gonzalez-Baradat, B., Eleizalde, M., Gonzalez-Marcano, E., Perrone, T. \& Mendoza, M., 2009, 'Trypanosoma evansi: A comparison of PCR and parasitological diagnostic tests in experimentally infected mice', Experimental Parasitology 121(1), 1-7. https://doi.org/10.1016/j.exppara.2008.09.013

González, E., González-Baradat, B., González, R., Linares, N., Mijares, A., Perrone, T. et al., 2006, 'Desarrollo de la técnica de reacción en cadena de la polimerasa para el diagnóstico de la trypanosomosis animal causada por Trypanosoma evansi', Agronomia Trop 56, 496-500.

Herrera, H.M., Davila, A.M.R., Norek, A., Abreu, U.G., Souza, S.S., D’Andrea, P.S. et al., 2004, 'Enzotiology of Trypanosoma evansi in Pantanal', Brazilian Journal of Veterinary Parasitology 125(3-4), 263-275. https://doi.org/10.1016/j.vetpar. 2004.07.013

Herrera, H.M., Norek, A., Freitas, T.P., Rademaker, V., Fernandes, O. \& Jansen, A.M. 2005, 'Domestic and wild mammals infection by Trypanosoma evansi in a pristine area of the Brazilian Pantanal region', Parasitology Research 96(2), 121-126. 
Hilali, M., Abdel-Gawad, A., Nassar, A., Abdel-Wahab, A., Magnusb, E. \& Büscher, P. 2004, 'Evaluation of the card agglutination test (CATT/T. evansi) for detection of Trypanosoma evansi infection in water buffaloes (Bubalus bubalis) in Egypt', Veterinary Parasitology 121(1-2), 45-51. https://doi.org/10.1016/j.vetpar.2004 Veterin
02.009

Holland, W.G., Claes, F., My, L.N., Thanh, N.G., Tam, P.T., Verloo, D. et al., 2001, 'A comparative evaluation of parasitological tests and a PCR for Trypanosoma evansi diagnosis in experimentally infected water buffaloes', Veterinary Parasitology diagnosis in

Konnai, S., Mekata, H., Mingala, C.N., Abes, N.S., Gutierrez, C.A., Herrera, J.R. et al., 2009, 'Development and application of a quantitative real-time PCR for the diagnosis of Surra in water buffaloes', Infection, Genetics and Evolution 9(4), 449-452. https://doi.org/10.1016/j.meegid.2009.01.006

Luckins, A.G., 1988, 'Trypanosoma evansi in Asia', Parasitology Today 4(5), 137-142. https://doi.org/10.1016/0169-4758(88)90188-3

Masiga, D.K., Smyth, A.J., Hayes, P., Bromidge, T.J. \& Gibson, W.C., 1992, 'Sensitive detection of trypanosomes in tsetse flies by DNA amplification', Internationa Journal for Parasitology 22(7), 909-918. https://doi.org/10.1016/0020-7519(92) 90047-O

Maudlin, I., Holmes, P.H. \& Miles, M.A., 2004, The trypanosomiasis, pp. 25-30, 283-331, CABI Publishing CAB International, Oxfordshire, UK.

Nantulya, V.M., 1990, 'Trypanosomiasis in domestic animals: The problems of diagnosis', Revue Scientifique et Technique (International Office of Epizootics) 9 , 357-367. https://doi.org/10.20506/rst.9.2.507

Omer, O.H., Mousa, H.M. \& Al-Wabel, N., 2007, 'Study on the antioxidant status of rats experimentally infected with Trypanosoma evansi', Veterinary Parasitology 145(1-2), 142-145. https://doi.org/10.1016/j.vetpar.2006.11.007

Otto, M.A., Da Silva, A.S., Gressler, L.T., Farret, M.H., Tavares, K.C. \& Zanette, R.A., 2010, 'Susceptibility of Trypanosoma evansi to human blood and plasma in infected mice', Veterinary Parasitology 168(1-2), 1-4.

Ramírez-Iglesias, J., Eleizalde, M., Gómez-Piñeres, E. \& Mendoza, M., 2011 'Trypanosoma evansi: A comparative study of four diagnostic techniques for trypanosomosis using rabbit as an experimental model', Experimental Parasitology $128,91-96$

Reid, S.A., 2002, 'Trypanosoma evansi control and containment in Australasia', Trends in Parasitology 18(5), 219-224. https://doi.org/10.1016/S1471-4922(02)02250-X

Rjeibi, M.R., Ben Hamida, T., Dalgatova, Z., Mahjoub, T., Rejeb, A., Dridi, W. et al., 2015, 'First report of surra (Trypanosoma evansi infection) in a Tunisian dog', Parasite 22, 3: 1-4 https://doi.org/10.1051/parasite/2015004
Saleh, M.A., Bassam, M.A. \& Sanousi, S.A., 2009, 'Oxidative stress in blood of camels (Camelus dromedaries) naturally infected with Trypanosoma evansi', Veterinary Parasitology 162(3-4), 192-199. https://doi.org/10.1016/j.vetpar.2009.03.035

Sambrook, J. \& Russell, D.W., 2001, Molecular cloning: A laboratory manual, Cold Spring Harbor Laboratory Press, Cold Spring Harbor, NY.

Sarataphan, N., Unjit, K., Vongpakorn, M. \& Indrakamhaeng, P., 2007, 'Real-time PCR for detection of Trypanosoma evansi in blood samples using SYBR Green I fluorescent dye', in Proceeding developing methodologies for the use of polymerase chain reaction in the diagnosis and monitoring of trypanosomosis, International Atomic Energy Agency, Animal Production and Health Section, Joint FAO/IAEA Division, Vienna, Austria; 294 p; Jun 2007; pp. 93-102, viewed June 2007, from, http://www-pub.iaea.org/MTCD/publications/PDF/te_1559 web.pdf.

Sengupta, P.P., Balumahendirana, M., Suryanaryanab, W., Raghaven-dra, A.G., Shomea, B.R., Gajendragada, M.R. et al., 2010, 'PCR-based diagnosis of surra-targeting VSG gene: Experimental studies in small laboratory rodents and buffalo', Veterinary Parasitology 171(2), 22-31. https://doi.org/10.1016/j.vetpar.2010.03.011

Sharma, A.K., Pallesen, L.J., Spang, R.J. \& Walden, W.E., 2010, 'Cytosolic iron-sulfur cluster assembly (CIA) system: Factors, mechanism, and relevance to cellular iron regulation', Journal of Biological Chemistry 285(35), 26745-26751. https://doi. org/10.1074/jbc.R110.122218

Sharma, P., Juyal, P.D., Singla, L.D., Chachra, D. \& Pawar, H., 2012, 'Comparative evaluation of real time conventional parasitological techniques for diagnosis of Trypanosoma evansi in cattle and buffaloes', Veterinary Parasitology 190(3-4), 375-382. https://doi.org/10.1016/j.vetpar.2012.07.005

Shumei, Z., Yongzhi, Z., Yunfei, W. \& Renjian, Z., 1996, 'Comparative study on different methods of preseving Trypanosoma evansi by liquidnitrogen cryofreezing', Chinese Journal of Veterinary Parasitology 4, 23-27.

Sukhumsirichart, W., Khuchareonaworn, S., Sarataphan, N., Viseshakul, N. \& Chansiri, K., 2000, 'Application of PCR-based assay for diagnosis of Trypanosoma evansi in different animals and vectors', The Journal of Tropical Medicine and Parasitology 23, 1-6.

Taylor, T.K., Boyle, D.B. \& Bingham, J., 2008, 'Development of a TaqMan PCR assay for the detection of Trypanosoma evansi, the agent of surra', Veterinary Parasitology 153(3-4), 255-264. https://doi.org/10.1016/j.vetpar.2008.01.045

Viljoen, G.J. \& Luckins, A.G., 2012, 'The role of nuclear technologies in the diagnosis and control of livestock diseases - A review', Tropical Animal Health and Production 44(7), 1341-1366. https://doi.org/10.1007/s11250-012-0077-5

Woo, P.T.K., 1970, 'The haematocrit centrifuge technique for the diagnosis of African trypanosomes', Acta Tropica 27, 384-386. 